\title{
Monitoring of Serological Status in Response to PPR Vaccination in the Goat Population of Parbat, Baglung and Myagdi District of Nepal
}

\author{
B. Regmi ${ }^{1 *}$, I. Dhakal ${ }^{2}$, M. K. Shah ${ }^{3}$ and K. R. Pande ${ }^{1}$ \\ ${ }^{1}$ Veterinary Laboratory, Pokhara \\ ${ }^{2}$ Army Equine Breeding Center, Nepal Army, Chitwan \\ ${ }^{3}$ Department of Surgery and Pharmacology, AFU, Chitwan, Nepal \\ *Corresponding author: regmibharat2008@gmail.com
}

\begin{abstract}
Peste des Petits ruminants (PPR) is a highly contagious trans-boundary animal disease associated with 100\% morbidity and 80-90\% mortality in goat herds. The study was carried out to assess the immune status against PPRV in unvaccinated and post vaccinated flock as well as immune response as it relates to age, sex and breed using a homologous tissue culture PPR vaccine produced by National Vaccine Production Laboratory, Kathmandu, Nepal. A total 276 blood samples were randomly collected from different regions of Parbat, Baglung and Myagdi districts with a population of 0.0189 million goats. Out of these, 214 goats were vaccinated one month earlier and 62 were unvaccinated. PPR antibody was detected by using competitive enzyme linked immunosorbent assay (c-ELISA) (ID Screen, PPR competition test kit, IDvet France). Of the unvaccinated goats, 25.8\% (16/62) were sero-positive suggesting prior exposure to PPRV. In the vaccinated goats, $75.2 \%$ (161/214) were sero-positive and $2.8 \%(6 / 214)$ animals were doubtful, suggesting a significant proportion failed to respond to vaccination. The competition percentage $(S / N \% \pm S D)$ of post-immunization (49.19 \pm 32.19$)$ were significantly $(p<0.01)$ lower in comparison to the respective unvaccinated mean titre $(75.76 \pm 35.51)$. There is no significant effect of age, sex or breed on the antibody titre value in PPR vaccinated animals. The sero-prevalence of $P P R$ in unvaccinated animals suggested that these flocks are in high susceptibility to PPR outbreak and needs an implementation of control measures to reduce economic losses. Vaccination will increase the proportion of animals with a protective antibody level, however more investigation needs to be done to determine why almost one-quarter of animals failed to seroconvert to vaccination. Further detailed study is needed to find out the risk factors responsible for low prevalence of antibody against PPRV in the immunized flock.
\end{abstract}

Keywords: Sero-monitoring; PPR; Vaccination; Goats;

\section{INTRODUCTION}

Peste des petits ruminants (PPR) or "goat plague" is an acute or sub- acute, highly contagious viral disease of small ruminants with high morbidity and mortality that threatens the food security and sustainable livelihood of farmers (Gari et. al., 2017). The causative agent of PPR is Peste des petits ruminants virus (PPRV) belonging to the genus morbillivirus and family Paramyxoviridae. It is characterized by fever, mucopurulent occulo-nasal discharges, necrotizing and erosive stomatitis, severe enteritis, and pneumonia finally leading to death. 
PPR first outbreak was reported in terai (Dhanusha, Mahottari, Bara, Sarlahi, Rauthat) and Gorkha districts of Nepal in 1994 as epidemic disease of goats and officially recognized as PPR in 1995 (GF-TADs, 2017). PPR has affected more than 68 districts and established as endemic disease in many districts (VEC, 2015). It was the major TADs recorded in small ruminants during the year 2015 as there were 71 outbreaks with 18,261 and 7,118 animals affected and died respectively (VEC, 2015). This disease is still prevailing as endemic in many regions of country, causing huge economic losses every year.

Acharya et al. (2018) reported the sero-prevalence of PPR $82.60 \%$ in unvaccinated goat population in a study conducted in the Syangja and Kaski districts which are the neighboring districts of Parbat, Baglung and Myagdi and lies in the same eco-zone. Due to the endemicity of the disease, the Govt. of Nepal, National Vaccine Production Laboratory had started production of the PPR homologous vaccine using tissue culture technology since 2000 (http://www.cbpl.gov.np/content.php?id=2 ) with a aim to vaccinate all susceptible goats and sheep. The sero-prevalence found is unexpectedly high though mass vaccination is practiced every year and the government is investing huge amount of budget. Sero-monitoring of the antibody titre could be insightful indicator of national herd immunity. Therefore, the present study was aimed to find out the vaccination coverage, its success rate and associated risk factors contributing for the development of the safe titre level in the immunized herd.

\section{METHODOLOGY}

Site of Study: A cross sectional study was conducted in Parbat, Baglung and Myagdi districts. Parbat district covers an area of $494 \mathrm{~km}^{2}$, which lies $28^{\circ} 14^{\prime} 0^{\prime \prime} \mathrm{N}$ latitude and $83^{\circ} 31^{\prime} 0^{\prime \prime} \mathrm{E}$ longitude with the goat population of 0.0058 million. Baglung district covers an area of $1,784 \mathrm{~km}^{2}$, which lies latitude $28^{\circ} 16^{\prime} \mathrm{N}$ and $83^{\circ} 36^{\prime} \mathrm{E}$ longitude with the goat population of 0.0094 million. Myagdi district covers an area of $2,297 \mathrm{~km}^{2}$, which lies latitude $28.3417^{\circ} \mathrm{N}$ and $83.5666^{\circ} \mathrm{E}$ longitude with the goat population of 0.0037 million. These districts are located same eco-zone in the central part of Nepal with typical weather.

Sample Collection: All essential epidemiological information were collected on individual animal using a well-designed questionnaire. The data of PPR outbreaks, vaccination, animal census, and animal movement were collected from the veterinary hospital of aforementioned districts. A total of 276 blood sample was collected from the randomly selected goat. Among them, 214 goats were vaccinated one month earlier against PPR whereas 62 goats were unvaccinated. In particular, 92 blood samples from each district were collected. The collected sample was kept overnight at room temperature for separation of serum and the separated serum was stored in a serum vial and placed inside the cool box until it was transferred to at $-20^{\circ} \mathrm{C}$ in the laboratory.

Laboratory Techniques: Serum samples were analyzed at the Veterinary Laboratory, Pokhara, Nepal. The preserved serum samples were thawed and tested for the presence of PPR antibody by using c-ELISA kit according to the instruction of manufacturer company (ID Vet France) and the optical density (OD) readings were taken using ELISA micro plate reader (MultiSkan Company) with an inference filter of $450 \mathrm{~nm}$. This ELISA kit was $94.5 \%$ and $99.4 \%$ sensitivity and specificity respectively. 
$\frac{\mathrm{S}}{\mathrm{P}} \%=\left(\frac{\mathrm{ODs}}{\mathrm{ODnc}}\right) * 100$

ODs-optical density of sample, $\mathrm{OD}_{\mathrm{nc}}$ - optical density of negative control

The test serum samples showing less than 50 percent competition percentage (CP) of mean OD values of monoclonal control wells were considered as positive for PPR antibodies whereas samples having OD values more than 50 were considered negative (Table-1).

Statistical Analysis: The data entry and analysis were performed using MS-Excel 2013. The univariate analysis by using 2-tailed Chi-square test was conducted to find out the significant association between potential risk factors. Furthermore, logistic regression model was used to assess the association between the risks factors and the PPR disease. Association in the logistic regression model were considered significant when $\mathrm{p}<0.05$.

\section{ELISA Result}

Interpretation of ELISA result described by Manufacture Company

\begin{tabular}{|l|l|}
\hline Positive & if $\mathrm{S} / \mathrm{P} \% \leq 50 \%$ \\
\hline Doubtful & if $50<\mathrm{S} / \mathrm{N} \leq 60 \%$ \\
\hline Negative & if $\mathrm{S} / \mathrm{P} \%>60 \%$ \\
\hline
\end{tabular}

\section{RESULT AND DISCUSSION}

The overall sero-positive value of $73.74 \%, 76.86 \%$ and $75.13 \%$ were found in goat population of Parbat, Baglung and Myagdi districts, respectively with the vaccination coverage of $77.54 \%$ (Table-1).

Table 1. Overall percentage of sero- positive result in the goat population of three districts

\begin{tabular}{|l|r|r|r|r|r|r|}
\hline Result & \multicolumn{2}{|c|}{ Parbat } & \multicolumn{2}{|c|}{ Baglung } & \multicolumn{2}{|c|}{ Myagdi } \\
\hline Positive & 67 & $73.74 \%$ & 71 & $76.86 \%$ & 69 & $75.13 \%$ \\
\hline Negative & 24 & $25.24 \%$ & 18 & $13.04 \%$ & 21 & $22.7 \%$ \\
\hline Doubtful & 1 & $1.02 \%$ & 3 & $3.26 \%$ & 2 & $2.17 \%$ \\
\hline
\end{tabular}

In our study, the male and female ratio was found 0.14 (Table-2)

Table 2 Competition Percentage value for different variables

\begin{tabular}{|l|l|l|l|l|l|}
\hline \multirow{2}{*}{ Particulars } & \multicolumn{4}{|c|}{ Sero-positive percentage competition of vaccinated herds (S/N\% \pm SD) } \\
\cline { 2 - 6 } & \multicolumn{2}{|c|}{ Sex } & \multicolumn{3}{c|}{ Breed } \\
\hline Result & Female & Male & Khari & Boar & Chyangra \\
\hline Mean \pm SD & $45.03 \pm 29.59$ & $43.48 \pm 29.42$ & $43.56 \pm 29.35$ & $45.98 \pm 24.31$ & $47.75 \pm 35.51$ \\
\hline
\end{tabular}


Table 3. Herd structure and sex wise sero-positive result

\begin{tabular}{|l|r|r|r|r|r|}
\hline & Herd Structure & \multicolumn{3}{|c|}{ Sero- positive Result (\%) } \\
\hline Sex & & & Positive & Negative & Doubtful \\
\hline Male & 33 & $12 \%$ & $76.19 \%$ & $23.81 \%$ & 0 \\
\hline Female & 243 & $88 \%$ & $76.86 \%$ & $21.71 \%$ & $1.43 \%$ \\
\hline
\end{tabular}

The above finding suggests that the farmers only rear buck for breeding purpose for longer duration. In the vaccinated goat population $(\mathrm{n}=214), 75.2 \%(161 / 214)$ were found sero-positive to PPR vaccines with the CP $49.19 \pm 32.19$, this means that the vaccinated herds are protected against PPRV, while 2.8\% (6/214) were found doubtful (Table-3).

Table 4. Competition Percentage (CP) of vaccinated and unvaccinated herds, showing vaccination coverage of $77.54 \%$

\begin{tabular}{|c|c|c|c|c|c|c|}
\hline \multicolumn{7}{|c|}{ Vaccination status } \\
\hline & \multicolumn{3}{|c|}{ Vaccinated $(n=214)$} & \multicolumn{3}{|c|}{ Unvaccinated $(n=62)$} \\
\hline Particulars & Sero-positive & $\begin{array}{l}\text { Sero- } \\
\text { negative }\end{array}$ & Doubtful & Seropositive & $\begin{array}{l}\text { Sero- } \\
\text { negative }\end{array}$ & Doubtful \\
\hline Result & $\begin{array}{l}75.2 \% \\
(161 / 214)\end{array}$ & $\begin{array}{l}21.74 \% \\
(47 / 214)\end{array}$ & $\begin{array}{l}2.8 \% \\
(6 / 214)\end{array}$ & $\begin{array}{l}25.8 \% \\
(16 / 62)\end{array}$ & $\begin{array}{l}74.19 \% \\
(46 / 62)\end{array}$ & 0 \\
\hline $\begin{array}{l}\text { (S/N\%) } \\
\pm \mathrm{SD}\end{array}$ & \multicolumn{3}{|c|}{$49.19 \pm 32.19$} & \multicolumn{3}{|c|}{$75.76 \pm 35.51$} \\
\hline
\end{tabular}

The findings of present study is consistent with the study of Kabir et.al., (2016) where they found sero-prevalence and sero-negative as $75 \%$ and $25 \%$, respectively in goats of Bangladesh. However, Luka et.al., (2011) had reported PPRV specific antibody sero-conversion of 55.26\% (84/152) (among Vaccinated) in Uganda which is much lesser than the finding of present study.

Similarly, out of 62 unvaccinated goats, $25.8 \%$ (16/62) were found sero-positive with the CP value of $75.76 \pm 35.51(>60)$, this means that these herds are very prone to PPR disease (Table- 3 ). Rahman et.al., (2016) found the sero-prevalence of $38.77 \%$ in the non-immunized herd which is higher than the sero-prevalence recorded in this study (25.8\%). Acharya et al. (2018) recorded sero-prevalence of $82.60 \%$ in a study conducted in the unvaccinated goat population of Syangja and Kaski districts which is higher than the finding of this study. Detection of PPRV antibodies can confirm the diagnosis of PPR disease in the unvaccinated herds, however the presence of maternal antibodies may yield false picture of the prevalence of infection. Thus, the isolation of PPR virus in clinical samples becomes essential in such condition because it is a gold standard test for confirmation of PPR virus (Mehmood et.al., 2009).

The $\mathrm{CP}$ for unvaccinated herds is significantly higher $(\mathrm{P}<0.01)$ than the immunized herds which means that the antibody titre value required to protect the animal from PPRV is sufficiently developed in the vaccinated animals. But the sero-positivity of only $75.2 \%$ suggests that the $25 \%$ vaccinated population failed to develop immunity. It was estimated that minimum of $75-80 \%$ 
herd immunity is essential for controlling the rinderpest, a related disease (Rossiter and James, 1989). If we consider this fact, the herd immunity in the vaccinated flock in the present study is somewhat satisfactory. There may be several factors contributing for successful outcome of the vaccination campaign like cold chain maintenance, duration of reconstituted vaccine, skill of vaccinators, area coverage and the health condition of animals during the immunization time.

In this study, there was no any association of individual factors (sex, breed) to develop immunity (Ab-titre) after PPR vaccination. The CP for male and female was $43.48 \pm 29.42$ and $45.03 \pm 29.59$ respectively. Similarly, the sero-positivity was found $76.19 \%$ and $76.86 \%$ for male and female respectively (Table- 4$)$.

\section{CONCLUSION}

The sero-positivity of PPR in unvaccinated population suggests that these animals are highly prone to PPR disease and there is a need to implement the PPR disease control measures to reduce the economic losses. Vaccination has markedly increased the proportion of animals with a protective antibody level. The further study is needed to probe the risk factors that are responsible for only $75 \%$ protection against PPRV in the immunized flock and to look for the reason why one-quarter of animals failed to seroconvert to vaccination.

\section{RECOMMENDATION}

The effectiveness of PPR vaccination also depends on the level of vaccine coverage. High herd immunity levels prevent virus transmission and low herd immunity levels encourage epidemic transmission as well as intermediate levels of immunity assist the establishment of endemicity (Rossiter and James, 1989). Therefore, it is essential to increase the coverage of immunization by implementing different vaccination strategies.

\section{ACKNOWLEDGEMENT}

The authors are very grateful to the farmers who cooperated during sample collection. As well as the technicians of Veterinary Lab, Pokhara are also highly accredited for their contribution in the time of sample collection.

\section{Conflict of Interest}

The authors declare that there is no conflict of interest.

\section{REFERENCES}

Acharya, N., Poudel, S. P., and Acharya, K. P. (2018). Cross-sectional sero-prevalence study of Peste des Petits Ruminants (PPR) in goats of Syangja and Kaski districts of Nepal. VirusDisease, 29 (2), 173-179. https://doi.org/10.1007/s13337-018-0449-1

Gari, G., Serda, B., Negesa, D., Lemma, F., and Asgedom, H. (2017). Serological Investigation of Peste Des Petits Ruminants in East Shewa and Arsi Zones, Oromia Region, Ethiopia. Veterinary Medicine International, 2017, 1-5. https://doi.org/10.1155/2017/9769071

Kabir, M. E., Hossain, M. M., Ershaduzzaman, M., Yousuf, M. A., and Islam, M. R. (2016). 
Sero-surveillance and sero-monitoring of locally produced PPR vaccine in the field and experimental level. Asian Journal of Medical and Biological Research, 2 (1), 33-37. https://doi.org/10.3329/ajmbr.v2i1.27566

GF-TADs (2017). Situation assessment of PPR and Way forward for SAARC countries.http://www.rrasia.oie.int/fileadmin/Regional_Representation/Programme/G_GFTADs/2017_SAARC_ GF-TADs/Session 4.2 PPR Nepal.pdf

Mehmood, A., Ali, Q., Ali Gadahi, J., Akbar Malik, S., and Imam Shah, S. (2009). Detection of Peste des Petits Ruminants (PPR) virus antibodies in sheep and goat populations of the North West Frontier Province (NWFP) of Pakistan by competitive ELISA (cELISA). Veterinary World,2 (9), 333-336

Luka, P. D., Erume, J., Mwiine, F. N., and Ayebazibwe, C. (2011). Seroprevalence of Peste des petits ruminants Antibodies in Sheep and Goats after Vaccination in Karamoja, Uganda: Implication on Control. International Journal of Animal and Veterinary Advances,3 (1), $18-22$.

Rahman, M. M., Alam, K. J., Alam, M. S., Hasan, M. M., and Moonmoon, M. (2016). A study on prevalence of peste des petits ruminant (PPR) in goat at Bagmara upazilla at Rajshahi district in Bangladesh. Research in Agriculture Livestock and Fisheries, 3 (2), 339-344. https://doi.org/10.3329/ralf.v3i2.29362

Rossiter, P. B., and James, A. D. (1989). An epidemiological model of rinderpest. II. Simulations of the behaviour of rinderpest virus in populations. Tropical Animal Health and Production, 21 (1), 69-84.

VEC. (2015). Annual Epidemiological Bulletin.http://epivet.gov.np/uploads/files/6021247917.pdf 